\title{
Pulsed Doppler Assessment of Left Ventricular Diastolic Filling in Children with Left Ventricular Outflow Obstruction Before and After Balloon Angioplasty
}

\author{
Jon N. Meliones, MD, A. Rebecca Snider, MD, Gerald A. Serwer, MD, Elizabeth M. Shaffer, MD, \\ Albert P. Rocchini, MD, Robert H. Beekman, MD, Amnon Rosenthal, MD, \\ MacDonald Dick, II, MD, Jane Peters, and Patricia Reynolds
}

\begin{abstract}
To assess left ventricular (LV) diastolic filling in children with pressure overload hypertrophy, 12 patients with LV outflow obstruction (7 with aortic valve stenosis and 5 with aortic coarctation) and 12 healthy, age-matched control subjects were examined. Each child underwent $M$-mode echocardiography and pulsed Doppler examination of the $L V$ inflow. The patients with LV outflow obstruction had cardiac catheterization and balloon angioplasty. Their echo/Doppler examinations were performed in the catheterization laboratory before and immediately after balloon angioplasty. From the M-mode echocardiogram, the LV cavity dimensions and wall thicknesses, LV mass and shortening fraction were measured. The following measurements were made from the Doppler recording: peak velocities at rapid ventricular filling (peak $E$ ) and during atrial contraction (peak $A$ ), ratio of peak $E$ to peak $A$ velocities, total area under the Doppler curve, percent of the total Doppler area occurring in the first onethird of diastole ( 0.33 area fraction), percent of the total area occurring under the $E$ wave ( $E$ area fraction), percent of the total area occurring under the $A$ wave ( $A$ area fraction) and the ratio of $E$ area to A area.
\end{abstract}

Before balloon angioplasty, the patients with $L V$ outflow obstruction had higher peak E velocity (1.06 \pm 0.18 vs $0.88 \pm 0.11 \mathrm{~m} / \mathrm{s}, \mathrm{p}<0.01)$, higher peak $A$ velocity $(0.86 \pm 0.22$ vs $0.47 \pm 0.08 \mathrm{~m} / \mathrm{s}$, p $<0.01)$ and lower $E / A$ velocity ratio $(1.29 \pm 0.27$ vs $1.93 \pm 0.34, p<0.01$ ) than the normal subjects. In the patient group, 0.33 area fraction was significantly lower $(0.38 \pm 0.07$ vs $0.57 \pm 0.09, p$ $<0.01)$ and $A$ area fraction was significantly higher $(0.44 \pm 0.14$ vs $0.23 \pm 0.07, p<0.01)$ than in the normal subjects. Also, patients with LV outflow obstruction had greater LV wall thickness, smaller LV cavity dimensions and greater LV mass compared with normal subjects. In patients before and after balloon angioplasty, there was a significant decrease in LV outflow gradient $(64 \pm 23$ vs $33 \pm 22$ $\mathrm{mm} \mathrm{Hg}, \mathrm{p}<0.01$ ), but there was no change in any echo/Doppler measurement. Thus, children with LV outflow obstruction have abnormal LV early dia. stolic relaxation with a shift in filling toward late diastole. Immediately after successful relief of the systolic pressure overload, diastolic filling patterns are unchanged, suggesting that hypertrophy rather than afterload mismatch is the primary determinant of the impaired relaxation.

(Am J Cardiol 1989;63:231-236)

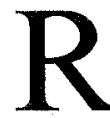
ecent studies using noninvasive techniques show that abnormal patterns of left ventricular (LV) diastolic filling occur in patients with aortic ste. nosis. M-Inode echocardiographic studies have shown decreased $L V$ relaxation rates, decreased $L V$ posterior wall thinning rates, prolonged $\mathrm{LV}$ relaxation times and decreased percent of total diastolic flow occurring dur ing rapid filling in patients with pressure overload hypertrophy compared with normal subjects. ${ }^{1-4}$ Pulsed Doppler echocardiography is another noninvasive technique that has been used to evaluate $\mathrm{LV}$ diastolic fill ing. ${ }^{5-12}$ Doppler diastolic indexes have correlated closely with those measured from cineangiography ${ }^{5}$ and radionuclide angiography. $8,13,14$ From the mitral valve Doppler recording, peak flow velocities, filling rates and the proportion of flow in the various phases of diastole can be measured. In this study, we hypothesized that children with pressure overload hypertrophy due to LV outflow obstruction have abnormalities of LV diastolic filling. Further, if hypertrophy rather than afterload mismatch were the principal determinant of impaired diastolic filling, then diastolic filling should be unchanged immediately after successful relief of the systolic pressure overload. To test this hypothesis, we assessed LV diastolic filling with Doppler echocardiography in a group of children with LV outflow obstruction before and immediately after balloon angioplasty.

\footnotetext{
From the Department of Pediatrics, C.S. Mott Children's Hospital, University of Michigan Medical Center, Ann Arbor, Michigan. Manuscript received June 29, 1988; revised manuscript received and accepted September 23, 1988.

Address for reprints: A. Rebeeca Snider, MD, F1609, C.S. Motr Children's Hospital, University of Michigan Medical Center, Ann Arbor, Michigan 48109.
} 


\section{METHODS}

Patients: The study included 12 children with I.V outflow obstruction and 12 age-matched, normal control subjects. The normal group consisted of 4 girls and 8 boys with no evidence of heart disease on physical examination or by echocardiography. They were 3 to 17 years old (mean 8.6) and weighed 12.3 to $73 \mathrm{~kg}$ (mean 33).

The patient group included 5 girls and 7 boys who were randomly selected from all children with LV outflow obstruction undergoing cardiac catheterization between June 1985 and September 1987. Selection criteria included (1) evidence of significant $\mathrm{LV}$ outflow tract gradient by physical examination, echocardiography and cardiac catheterization, (2) presence of obstruction severe enough to require treatment with balloon angioplasty, (3) absence of additional congenital defects such as mitral stenosis, left-to-right shunts or right ventricular outflow obstruction and (4) absence of significant aortic or mitral regurgitation by cineangiography before and after balloon angioplasty. The patient group was 3 to 17 years old (mean 8.6) and weighed from 16 to 64 $\mathrm{kg}$ (mean 31.5). Seven children had aortic valve stenosis and 5 had coarctation of the aorta. Three of the aortic stenosis patients had a previous aortic valvulotomy in infancy, 1 had previous balloon valvuloplasty and 2 coarctation patients had previous surgical repair of the coarctation. No patients were receiving cardiac medications.

Cardiac catheterization: The patient group underwent left- and right-sided heart catheterization after being premedicated with diphenhydramine and droperidol. Peak-to-peak pressure gradients across the obstruction and thermodilution cardiac indexes were measured before and after balloon dilatation. Left ventricular cineangiograms were obtained in all patients before balloon angioplasty and in all aortic stenosis patients after balloon angioplasty. Aortic cineangiograms were obtained in all patients before and after balloon angioplasty.

Echocardiographic examination: All study participants underwent an M-mode echocardiographic examination of the left ventricle and a pulsed Doppler examination of the LV inflow. The control subjects were examined at rest in the echocardiography laboratory; the patients were examined in the cardiac catheterization laboratory both before and immediately after balloon angioplasty.

M-MODE ECHOCARDIOGRAPHIC STUDIES: M-mode echocardiograms of the left ventricle were generated from the 2-dimensional sector scanner (Advanced Technology Laboratories Mark 600 or Ultramark 8, 3- or 5$\mathrm{MHz}$ transducers) using a cursor line positioned at the free edges of the mitral valve leaflets in the parasternal short-axis view. From the M-mode echocardiogram, the LV posterior wall, septum and LV dimension were measured at end-diastole at the beginning of the $Q$ wave on the electrocardiogram. ${ }^{15,16}$ The LV dimension at endsystole was measured as the smallest systolic dimension. The shortening fraction was calculated as the change in LV dimension that occurred from end-diastole to endsystole divided by the LV end-diastolic dimension. The LV mass was calculated using the Penn convention and the following formula: ${ }^{17,18}$

$$
\begin{aligned}
\mathrm{LV} \text { mass }= & 1.04\left([\mathrm{LVDD}+\mathrm{LVPW}+\mathrm{IVS}]^{3}\right. \\
& \left.-[\mathrm{LVDD}]^{3}\right)-13.6 \mathrm{~g},
\end{aligned}
$$

where LVDD = left ventricular end-diastolic dimension; LVPW = left ventricular posterior wall thickness in diastole; and IVS = interventricular septal thickness in diastole. Indexed LV mass was obtained by dividing LV mass by the body surface area.

PULSED DOPPLER STUDIES: Pulsed Doppler examinations of the LV inflow were obtained using the apical 4chamber view for operator guidance. The Doppler cursor line and sample volume were placed in the mitral valve funnel at an angle as parallel to flow as possible. The sample volume position was adjusted so as to record maximal velocities through the mitral valve (usually near the tips of the leaflets). The Doppler examinations were recorded simultaneous with the electrocardiogram at paper speeds of $50 \mathrm{~mm} / \mathrm{s}$. From the Doppler spectral recordings, the peak velocities during rapid ventricular filling (peak E) and atrial contraction (peak A) were measured for at least 3 cardiac cycles and the ratio of peak $E$ to peak $A$ velocities was calculated.

To examine the Doppler patterns of LV diastolic filling, several areas under the Doppler spectral tracing were integrated using methods previously described by us. ${ }^{6,9}$ The measured areas (Figure 1) included: (1) the

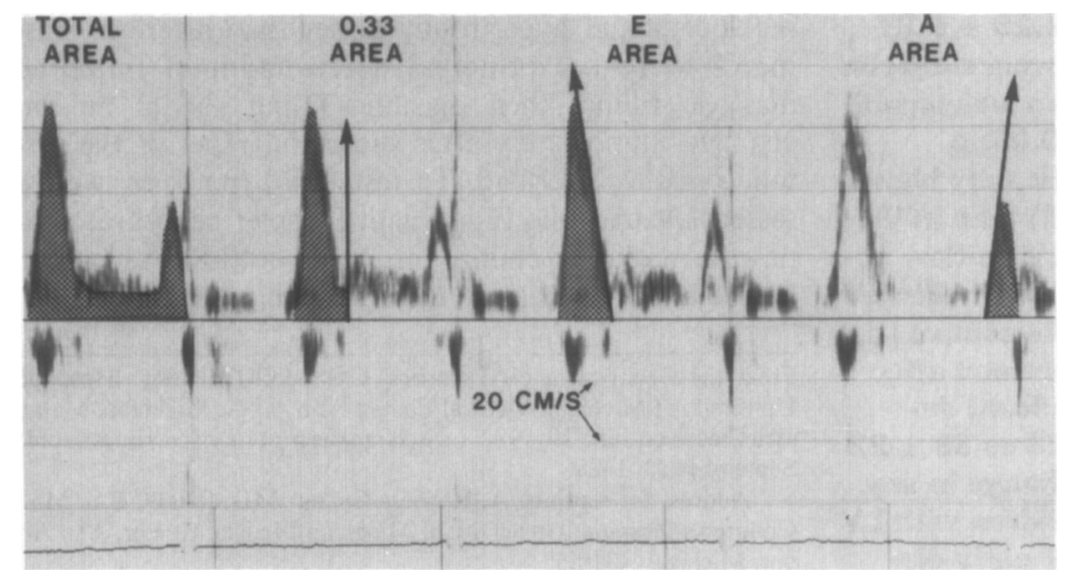

FIGURE 1. Mitral valve Doppler recording showing the areas that were measured. 


\begin{tabular}{|c|c|c|c|c|c|c|c|c|c|c|c|c|c|c|c|c|c|c|c|}
\hline \multirow[b]{2}{*}{ Pts } & \multirow{2}{*}{$\begin{array}{l}\text { Age } \\
\text { (yrs) }\end{array}$} & \multicolumn{2}{|c|}{ Peak E } & \multicolumn{2}{|c|}{ Peak $\Lambda$} & \multicolumn{2}{|c|}{ Peak $E / \wedge$} & \multicolumn{2}{|l|}{$T \Lambda$} & \multicolumn{2}{|c|}{$\begin{array}{l}0.33 \text { Area/ } \\
\mathrm{TA}\end{array}$} & \multicolumn{2}{|c|}{ E Area/TA } & \multicolumn{2}{|c|}{ A Area/TA } & \multicolumn{2}{|c|}{ E/A Area } & \multicolumn{2}{|c|}{ HR (bpm) } \\
\hline & & Pre & Post & Pre & Post & Pre & Post & Pre & Post & Pre & Post & Pre & Post & Pre & Post & Pre & Post & Pre & Post \\
\hline 1 & 16 & 1.01 & 0.98 & 0.70 & 0.55 & 1.45 & 1.80 & 0.19 & 0.14 & 0.44 & 0.54 & 0.71 & 0.67 & 0.34 & 0.35 & 2.07 & 1.94 & 85 & 83 \\
\hline 2 & 6 & 1.06 & 1.07 & 0.83 & 0.88 & 1.28 & 1.21 & 0.23 & 0.24 & 0.43 & 0.41 & 0.76 & 0.74 & 0.33 & 0.36 & 2.31 & 2.05 & 81 & 86 \\
\hline 3 & 9 & 0.92 & 1.02 & 0.61 & 0.46 & 1.52 & 2.25 & 0.21 & 0.15 & 0.43 & 0.65 & 0.74 & 0.78 & $0.3 ?$ & $0.7 ?$ & 2.34 & 3.55 & 77 & 69 \\
\hline 4 & 5 & 1.13 & 1.09 & 0.76 & 0.76 & 1.49 & 1.45 & 0.20 & 0.22 & 0.46 & 0.43 & 0.74 & 0.75 & 0.42 & 0.32 & 1.75 & 2.34 & 87 & 89 \\
\hline 5 & 4 & 1.30 & 1.37 & 1.26 & 1.31 & 1.03 & 1.05 & 0.22 & 0.22 & 0.35 & 0.34 & 0.65 & 0.61 & 0.64 & 0.60 & 1.02 & 1.02 & 93 & 94 \\
\hline 6 & 3 & 1.03 & 1.03 & 0.90 & 1.01 & 1.14 & 1.02 & 0.15 & 0.19 & 0.27 & 0.32 & 0.73 & 0.70 & 0.57 & 0.56 & 1.28 & 1.25 & 91 & 103 \\
\hline 7 & 17 & 0.75 & 0.94 & 0.45 & 0.59 & 1.68 & 1.59 & 0.18 & 0.21 & 0.46 & 0.46 & 0.70 & 0.76 & 0.29 & 0.30 & 2.44 & 2.51 & 71 & 77 \\
\hline 8 & 11 & 1.45 & 1.79 & 0.86 & 1.08 & 1.68 & 1.66 & 0.26 & 0.30 & 0.41 & 0.41 & 0.74 & 0.70 & 0.29 & 0.34 & 2.57 & 2.10 & 87 & 87 \\
\hline 9 & 9 & 1.06 & 1.04 & 0.86 & 0.97 & 1.23 & 1.07 & 0.19 & 0.17 & 0.40 & 0.35 & 0.61 & 0.62 & 0.37 & 0.41 & 1.68 & 1.54 & 84 & 96 \\
\hline 10 & 7 & 1.06 & 0.93 & 1.09 & 0.81 & 0.97 & 1.15 & 0.17 & 0.17 & 0.30 & 0.41 & 0.68 & 0.67 & 0.65 & 0.36 & 1.06 & 1.89 & 98 & 83 \\
\hline 11 & 12 & 1.06 & 0.73 & 0.95 & 0.65 & 1.12 & 1.13 & 0.25 & 0.16 & 0.31 & 0.35 & 0.65 & 0.67 & 0.40 & 0.38 & 1.64 & 1.75 & 79 & 83 \\
\hline 12 & 4 & 0.93 & 1.09 & 1.03 & 1.10 & 0.90 & 0.99 & 0.14 & 0.16 & 0.26 & 0.29 & 0.65 & 0.68 & 0.60 & 0.62 & 1.09 & 1.09 & 104 & 108 \\
\hline Mean & 8.6 & 1.06 & 1.09 & 0.86 & 0.85 & 1.29 & 1.36 & 0.20 & 0.19 & 0.38 & 0.41 & 0.70 & 0.70 & 0.44 & 0.40 & 1.77 & 1.92 & 86 & 88 \\
\hline \multicolumn{20}{|c|}{ Normal Subjects } \\
\hline 1 & 16 & 0.92 & & 0.39 & & 2.37 & & 0.14 & & 0.71 & & 0.75 & & 0.15 & & 5.23 & & 62 & \\
\hline 2 & 6 & 0.86 & & 0.57 & & 1.53 & & 0.14 & & 0.50 & & 0.70 & & 0.26 & & 2.72 & & 93 & \\
\hline 3 & 9 & 0.81 & & 0.39 & & 2.07 & & 0.11 & & 0.70 & & 0.74 & & 0.19 & & 4.05 & & 64 & \\
\hline 4 & 5 & 0.81 & & 0.51 & & 1.60 & & 0.13 & & 0.46 & & 0.69 & & 0.32 & & 2.18 & & 91 & \\
\hline 5 & 4 & 1.03 & & 0.54 & & 1.96 & & 0.14 & & 0.49 & & 0.76 & & 0.26 & & 3.04 & & 100 & \\
\hline 6 & 3 & 0.95 & & 0.56 & & 1.70 & & 0.12 & & 0.47 & & 0.75 & & 0.27 & & 2.85 & & 101 & \\
\hline 7 & 17 & 0.86 & & 0.36 & & 2.39 & & 0.16 & & 0.70 & & 0.59 & & 0.13 & & 4.48 & & 48 & \\
\hline 8 & 10 & 0.90 & & 0.51 & & 1.79 & & 0.18 & & 0.52 & & 0.67 & & 0.34 & & 2.00 & & 79 & \\
\hline 9 & 10 & 0.81 & & 0.56 & & 1.45 & & 0.13 & & 0.54 & & 0.64 & & 0.28 & & 2.31 & & 78 & \\
\hline 10 & 7 & 0.98 & & 0.41 & & 2.38 & & 0.13 & & 0.63 & & 0.79 & & 0.14 & & 5.67 & & 85 & \\
\hline 11 & 11 & 0.64 & & 0.37 & & 1.77 & & 0.09 & & 0.50 & & 0.52 & & 0.23 & & 2.49 & & 68 & \\
\hline 12 & 5 & 0.98 & & 0.46 & & 2.17 & & 0.11 & & 0.59 & & 0.77 & & 0.24 & & 3.37 & & 91 & \\
\hline Mean & 8.6 & 0.88 & & 0.47 & & 1.93 & & 0.13 & & 0.57 & & 0.70 & & 0.23 & & 3.37 & & 80 & \\
\hline
\end{tabular}

total area under the velocity envelope throughout diastole, (2) the area under the velocity curve for the first $33 \%$ of diastole ( 0.33 area), (3) the E area or the triangular area formed by extrapolating a straight line down from the peak E vclocity to the bascline and (4) the A area or the triangular area formed by extrapolating a straight line from the peak A velocity to the baseline.

To determine the percent of the total velocity envelope occupied by the individual areas, the area fractions were calculated as the individual areas divided by the total Doppler area. Also, the ratio of the $\mathrm{E}$ and $\mathrm{A}$ areas was calculated.

All Doppler areas were traced using a cross-wire cursor, a microprocessor and commercially available computer software (Freeland Medical Systems). The Doppler areas were traced along the densest portion of the curve (the modal velocity). Doppler peak velocities were measured as the highest value of the velocity displayed at the outermost border of the spectral recording.

Statistical analysis: Three or more cardiac cycles were measured and averaged to obtain each $\mathrm{M}$-mode and Doppler echocardiographic value. Statistical comparisons between the control subjects and the patient group and between the patient group before and after balloon were made using paired $t$ tests. Adjustments were made for multiple comparisons and a 2-tailed $\mathrm{p}$ value $<0.05$ was used to indicate a significant inter- group difference. All values are reported as mean \pm standard deviation.

The relation between pre-balloon Doppler indexes and LV mass was assessed in the patient group using linear regression analysis; $\mathrm{p}<0.05$ was considered a significant correlation.

\section{RESULTS}

Patients: The patient group and the control group did not differ in age, weight or heart rate. At the time of cardiac catheterization, all members of the patient group had successful relief of their LV outflow obstruction with balloon angioplasty. Peak-to-peak systolic pressure gradient before balloon angioplasty $(64 \pm 23$ $\mathrm{mm} \mathrm{Hg}$ ) was significantly higher than that after ( $33 \pm$ $22 \mathrm{~mm} \mathrm{Hg}, \mathrm{p}<0.001$ ). Before and after balloon angioplasty, cardiac index ( $3.74 \pm 0.47$ vs $3.86 \pm 0.63$ liters/ $\left.\mathrm{min} / \mathrm{m}^{2}, \mathrm{p}=0.49\right)$ and $\mathrm{LV}$ end-diastolic pressure (14.5 \pm 4.9 vs $11.8 \pm 6.2 \mathrm{~mm} \mathrm{Hg}, \mathrm{p}=0.10$ ) were unchanged. No patient developed significant aortic or mitral regurgitation after balloon angioplasty.

Echocardiographic studies: Pulsed Doppler measurements for each individual patient and each control subject are listed in Table I.

COMPARISONS OF NORMAL SUBJECTS AND PATIENTS WITH LEFT VENTRICULAR OUTFLOW OBSTRUCTION BEFORE BAL LOON ANGIOPLASTY: Mean values for the Doppler measurements of the normal subjects and the patient group 


\begin{tabular}{|c|c|c|c|}
\hline & $\begin{array}{l}\text { Normal } \\
\text { Subjects }\end{array}$ & $\begin{array}{l}\text { Pre-Balloon } \\
\text { Patients }\end{array}$ & $\mathrm{p}$ Value \\
\hline Peak E (m/s) & $0.88 \pm 0.11$ & $1.06 \pm 0.18$ & $0.006^{*}$ \\
\hline Peak A (m/s) & $0.47 \pm 0.08$ & $0.86 \pm 0.22$ & $0.00003^{*}$ \\
\hline Ratio peak $E /$ peak $A$ & $1.93 \pm 0.34$ & $1.29 \pm 0.27$ & $0.0003^{*}$ \\
\hline Total area $(\mathrm{m})$ & $0.13 \pm 0.02$ & $0.20 \pm 0.04$ & $0^{*}$ \\
\hline 0.33 area $/$ total area & $0.57 \pm 0.09$ & $0.38 \pm 0.07$ & $0.00005^{*}$ \\
\hline E area/total area & $0.70 \pm 0.08$ & $0.70 \pm 0.05$ & 0.97 \\
\hline A area/total area & $0.23+0.07$ & $0.44 \pm 0.14$ & $0.001 *$ \\
\hline E area $/ A$ area & $3.37 \pm 1.22$ & $1.77 \pm 0.57$ & $0.002 *$ \\
\hline LVDD (cm) & $3.89 \pm 0.38$ & $3.59 \pm 0.54$ & $0.04 *$ \\
\hline $\operatorname{LVSD}(\mathrm{cm})$ & $2.46 \pm 0.33$ & $2.16 \pm 0.50$ & 0.10 \\
\hline$\%$ SF & $36.0 \pm 6.2$ & $40.3 \pm 7.5$ & 0.20 \\
\hline LVPW (cm) & $0.67 \pm 0.23$ & $0.85 \pm 0.29$ & $0.01 *$ \\
\hline Septum $(\mathrm{cm})$ & $0.65 \pm 0.22$ & $0.86 \pm 0.35$ & $0.03^{*}$ \\
\hline LV mass (g) & $73.8 \pm 30.0$ & $148.1 \pm 110.2$ & $0.03^{*}$ \\
\hline Mass index $\left(\mathrm{gm} / \mathrm{m}^{2}\right)$ & $73.7 \pm 24.6$ & $140.6 \pm 59.4$ & $0.008^{*}$ \\
\hline Heart rate (beats/min) & $80 \pm 17$ & $86 \pm 9$ & 0.09 \\
\hline
\end{tabular}

before balloon angioplasty are listed in Table II. The patient group had a higher peak $E$ velocity and a much higher peak A velocity than the control group; therefore, the ratio of peak $E$ to peak A velocity was significantly lower in the patient group. Total area under the velocity envelope was significantly lower in the normal subjects. In the patient group, the percent of the total Doppler area occurring in the first third of diastole was significantly lower and the percent of the total Doppler area occurring under the A wave was significantly higher. The percent of the total Doppler area occurring under the $\mathrm{E}$ wave was the same in the 2 groups; therefore, the ratio of $E$ area to $A$ area was significantly lower in the patient group.

The LV posterior wall and septal thickness and the LV mass were significantly greater in the patient group than in the normal subjects. The LV diastolic dimension of the patient group was smaller than that of the control

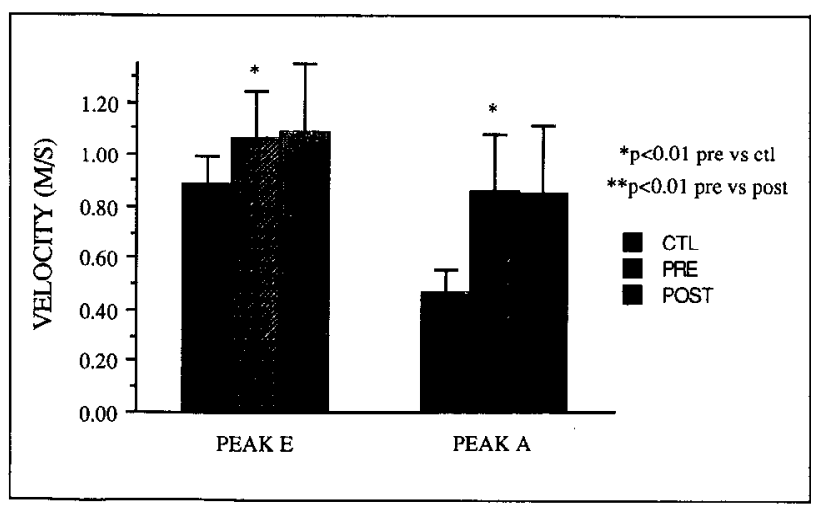

FIGURE 2. Doppler peak velocities measured in control (Ctl) subjects and patients with LV outflow obstruction before (Pre) and immediately after (Post) balloon angioplasty. A = velocity during atrial contraction; $E$ = velocity during rapid ventricular filling.
TABLE III Echo Measurements in Patients with Left Ventricular Outflow Obstruction Before and After Balloon Angioplasty

\begin{tabular}{|llll|}
\hline Measurement & Before & After & p Valuc \\
\hline Peak E (m/s) & $1.06 \pm 0.18$ & $1.09 \pm 0.26$ & 0.59 \\
Peak A (m/s) & $0.86 \pm 0.22$ & $0.85 \pm 0.26$ & 0.83 \\
Ratio peak E/peak A & $1.29 \pm 0.27$ & $1.36 \pm 0.39$ & 0.33 \\
Total area (m) & $0.20 \pm 0.04$ & $0.19 \pm 0.05$ & 0.69 \\
O.33 area/total area & $0.38 \pm 0.07$ & $0.41 \pm 0.10$ & 0.12 \\
E area/total area & $0.70 \pm 0.05$ & $0.70 \pm 0.05$ & 0.93 \\
A area/total area & $0.44 \pm 0.14$ & $0.40 \pm 0.13$ & 0.25 \\
E area/A area & $1.77 \pm 0.57$ & $1.92 \pm 0.70$ & 0.31 \\
LVDD (cm) & $3.59 \pm 0.54$ & $3.54 \pm 0.65$ & 0.68 \\
LVSD (cm) & $2.16 \pm 0.50$ & $2.03 \pm 0.66$ & 0.19 \\
\% SF & $10.3 \pm 7.5$ & $42.6 \pm 8.0$ & 0.29 \\
LVPW (cm) & $0.85 \pm 0.29$ & $0.93 \pm 0.26$ & 0.10 \\
Septum (cm) & $0.86 \pm 0.35$ & $0.88 \pm 0.29$ & 0.43 \\
Heart rate (beats /min) & $86 \pm 9$ & $88 \pm 11$ & 0.44 \\
\hline \multicolumn{2}{l}{ Values are mean \pm standard deviation. } & & \\
Abbreviations as in Table II. & & & \\
\hline
\end{tabular}

group. The 2 groups did not differ in LV systolic dimension or percent shortening fraction.

COMPARISONS OF PATIENTS WITH LEFT VENTRICULAR OUTFLOW OBSTRUCTION BEFORE AND AFTER BALLOON ANGIOPLASTY: No differences were observed in any Doppler velocities, area fractions or ratios following successful relief of the LV outflow obstruction (Table III). Mmode echocardiographic measurements of LV dimensions and shortening fraction did not change after balloon angioplasty.

Figures 2, 3 and 4 summarize the Doppler measurements that were most useful for distinguishing normal subjects from patients with LV outflow obstruction.

CORRELATION OF BEFORE BALLOON DOPPLER INDEXES WITH LEFT VENTRICULAR MASS: To determine if the severity of the diastolic filling abnormality was related to the extent of LV hypertrophy, each before-balloon Doppler index was correlated with indexed LV mass using linear regression analysis. None of the Doppler indexes correlated significantly with LV mass. The only variable that correlated with LV mass was the before-balloon catheterization gradient (correlation coefficient $=0.59, \mathrm{p}=$ 0.06 ); however, this relation did not reach statistical significance.

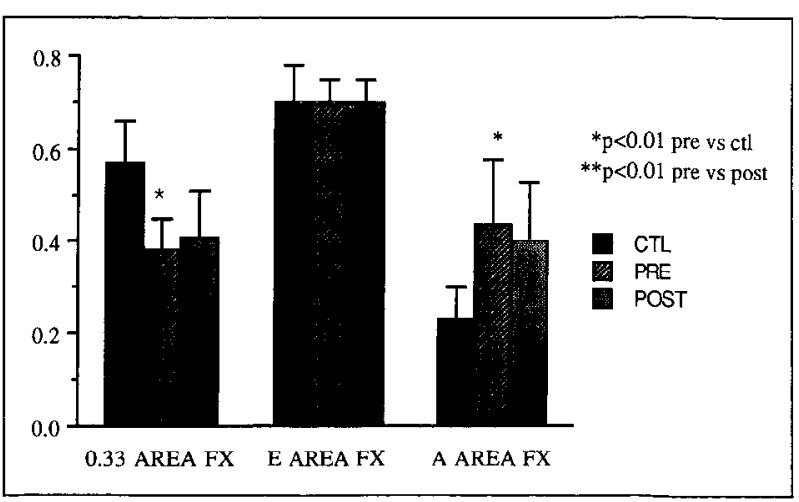

FIGURE 3. Doppler area fractions in control (Ct) subjects and patients with LV outflow obstruction before (Pre) and after (Post) balloon angioplasty. FX = fractions. 


\section{DISCUSSION}

This study shows that children with severe LV outflow obstruction have an abnormal pattern of LV diastolic filling detectable by mitral valve Doppler examination. The decrease in the percent of the total area in the first one-third of diastole and the increase in the percent of the total area under the A wave suggest a relative shift of $\mathrm{LV}$ filling to late diastole probably caused by impaired early diastolic relaxation.

Possible mechanisms of diastolic filling abnormalities: In children and adults with pressure overload hypertrophy, increased wall thickness or mass has been implicated as the cause of impaired LV relaxation. Several studies have shown a significant correlation between the extent of hypertrophy and the severity of the diastolic filling abnormality. ${ }^{4,19,20}$ In our study, the extent of hypertrophy (measured as indexed LV mass) did not correlate with any of the Doppler indexes of diastolic filling. Further, normal diastolic filling patterns have been reported in endurance-trained athletes with physiologic cardiac hypertrophy, making LV hypertrophy alone an unlikely cause of impaired LV relaxation..$^{21,22}$

If LV hypertrophy alone were the cause of impaired LV relaxation, then regression of LV hypertrophy should be accompanied by a return of diastolic filling patterns toward normal. This question could be addressed in long-term studies of patients who have had successful relief of $\mathrm{LV}$ outflow obstruction and resultant decrease in LV hypertrophy. We attempted such a study in our patient group; however, in the patients with aortic stenosis, Doppler gradients tended to reoccur within 1 to 2 years of balloon angioplasty and regression of LV hypertrophy did not occur. Such a long-term study may be possible in patients with coarctation of the aorta, in whom restenosis seldom occurs after successful balloon angioplasty.

The muscle load during contraction has an effect on the extent of muscle shortening and the rate of muscle lengthening. Failure to normalize LV wall stress (afterload mismatch) could account for the manifestations of impaired LV relaxation seen in patients with pressure overload hypertrophy. ${ }^{23-25}$ Since diastolic filling abnor- malities did not revert toward normal in our patient group following removal of the high afterload and reduction of LV systolic pressure to normal, it is unlikely that the filling abnormalities were caused by an afterload mismatch.

Finally, an interaction between subendocardial ischemia and changes in cytosolic calcium transport could cause the impaired myocardial relaxation seen in patients with hypertrophy. The interaction between these 2 factors could explain why impaired relaxation occurs in patients with pressure overload hypertrophy but not in young athletes with physiologic hypertrophy. 21,22

Factors affecting the mitral valve Doppler indexes: Diastolic indexes of LV relaxation can be influenced by several factors including age, heart rate, systolic function and LV loading conditions. ${ }^{15,23-25}$ Several studies have shown that the mitral valve Doppler indexes are affected by aging in normal adults. ${ }^{26,27}$ With increasing age, peak $E$ velocity decreases, peak $A$ velocity increases, E/A velocity ratio decreases and the $A$ area fraction increases. In this study, differences in LV diastolic filling patterns between the children with LV outflow obstruction and the normal children cannot be explained on the basis of age, heart rate, systolic function or LV loading conditions. The control and patient groups were age-matched and the heart rates of the 2 groups were not different. Both groups had normal systolic function, as assessed by M-mode shortening fraction. Changes in preload can alter the mitral valve diastolic filling indexes. ${ }^{28}$ In our study, the patients with LV outflow obstruction had a slightly smaller LV diastolic dimension compared to the normal children; however, at catheterization, their cardiac indexes were normal. Further, all children with significant aortic or mitral regurgitation (either before or after balloon angioplasty) were excluded from the study because they would be expected to have abnormal early diastolic filling duc to incrcascd preload. Finally, LV afterload was not the direct cause of the differences in LV filling observed between the patient and control groups as these differences did not change when the afterload was successfully decreased by balloon angioplasty.
FIGURE 4. Doppler ratios in control (CtI) subjects and patients with LV outflow obstruction before (Pre) and after (Post) balloon angioplasty.

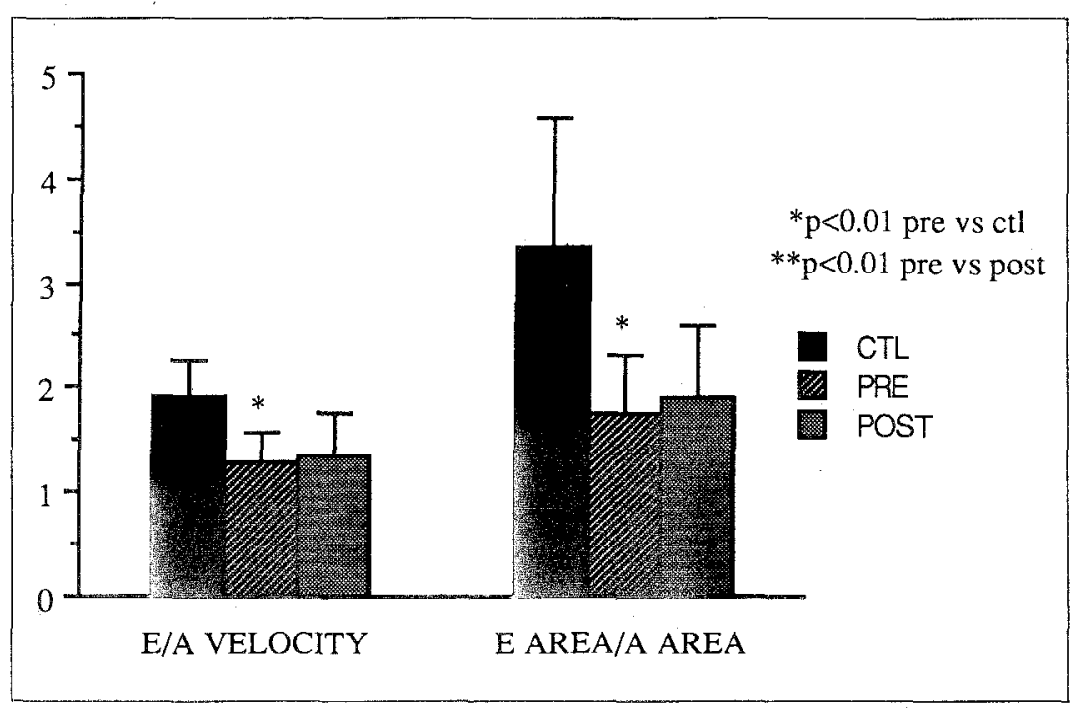


Although our control and patient groups did not differ in age, weight, body surface area or heart rate, it is interesting that the total area under the Doppler curve of the patient group was significantly larger than that of the control group. We believe that this difference is not due to differences in volumetric flow across the mitral valve but, rather, is due to an increase in LV filling pressure and a continuous decay of the LV pressure into late diastole that has been described in patients with severely impaired LV relaxation. ${ }^{21,28}$ The high LV filling pressures and continuous, slow rate of decay of the LV pressure into diastole result in a continuous large instantaneous pressure gradient between the left atrium and left ventricle throughout diastolc. With a continuous pressure gradient throughout diastole, mitral valve inflow velocities do not return to the baseline after the peak $E$ and before the peak $A$ velocities. Hence, the total area under the mitral valve Doppler recording is greater. Further investigations of simultaneously recorded left atrial and $L V$ pressures and mitral valve inflow Doppler tracings are needed to verify this explanation.

Acknowledgment: The authors with to thank Lyne Mcrida-Asmus for editorial assistance.

\section{REFERENCES}

1. Friedman MJ, Sahn DJ, Burris HA, Allen HD, Goldberg SJ. Computerized echocardiographic analysis to detect abnormal systolic and diastolic left ventricular function in children with aortic stenosis. Am J Cardiol 1979;44:478-486.

2. Hanrath $P$, Mathey $D G$, Siegert $R$, Bleifeld $W$. Left ventricular relaxation and filling pattern in different forms of left ventricular hypertrophy: an echocardiographic study. Am J Cardiol 1980;45:15-23.

3. Kramer PH, Djalaly A, Poehlmann H, Schiller NB. Abnormal diastolic left ventricular posterior wall motion in left ventricular hypertrophy. Am Heart $J$ 1983;5:1066-1069.

4. Fifer MA, Borow KM, Colan SD, Lorell BH. Early diastolic left ventricular function in children and adults with aortic stenosis. JACC 1985;5:1147-1154. 5. Rokey R, Kuo LC, Zoghbi WA, Limacher MC, Quinones MA. Determination of parameters of left ventricular diastolic filling with pulsed Doppler echocardiography: comparison with cineangiography. Circulation 1985;71:543-550.

6. Snider AR, Gidding SS, Rocchini AP, Rosenthal A, Dick M II, Crowley DC, Peters J. Doppler evaluation of left ventricular diastolic filing in children with systemic hypertension. Am J Cardiol 1985;56:921-926.

7. Fujii J, Yazaki Y, Sawada H, Aizawa T, Watanabe H, Kato K. Noninvasive assessment of left and right ventricular filling in myocardial infarction with a twodimensional Doppler echocardiographic method. JACC 1985;5:1155-1160.

8. Spirito P, Maron BJ, Bonow RO. Noninvasive assessment of left ventricular diastolic function: comparative analysis of Doppler echocardiographic and radio- nuclide angiographic techniques. $J A C C$ 1986;7:518-526.

9. Gidding SS, Snider AR, Rocchini AP, Peters J; Farnsworth R. Left ventricular diastolic filling in children with hypertrophic cardiomyopathy: assessment with pulsed Doppler echocardiography. JACC 1986;8:310-316.

10. Takenaka K, Dabestani A, Gardin JM, Russell D, Clark S, Allfie A. Left ventricular filling in hypertrophic cardiomyopathy: a pulscd Doppler cchocardiographic study. JACC 1986,7:1263-I271.

11. Maron BJ, Spirito $P$ Green $K J$, Wesley YE, Bonow RO, Arce J Noninvasive assessment of left ventricular diastolic function by pulsed Doppler echncardiography in patients with hypertrophic cardiomyopathy. JACC 1987;10:733-742. 12. Phillips RA, Coplan NL, Krakoff LR, Yeager K, Ross RS, Gorlin R, Goldman ME. Doppler echocardiographic analysis of left ventricular filling in treated hypertensive patients. JACC 1987;9:317-322.

13. Friedman BJ, Drinkovic N, Miles H, Shih W, Mazzoleni A, deMaria AN Assessment of left ventricular diastolic function: comparison of Doppler echocardiography and gated blood pool scintigraphy. JACC 1986:8:1348-1354.

14. Pearson AC, Goodgold $\mathrm{H}$, Labovitz AJ. Comparison of pulsed Doppler echocardiography and radionuclide angiography in the assessment of left ventricular filling. Am J Cardiol 1988;61:446-454.

15. Bahler RC, Vrobel TR, Martin $P$. The relation of heart rate and shortening fraction to echocardiographic indexes of left ventricular relaxation in normal subjects. JACC 1983;2:926-933.

16. Sahn DJ, DeMaria A, Kisslo J, Weyman A. Recommendations regarding quantitation in M-mode echocardiography: results of a survey of echocardiographic measurements. Circulation 1978-58:1072-1083.

17. Devereux RB, Reichek N. Echocardiographic determination of left ventricular mass in man. Ariatomic validation of the method. Circulation 1977;55:613618 .

18. Devereux RB, Casale PN, Kligficld P, Eiscnberg RR, Miller D, Campo E Alonso DR. Performance of primary and derived M-mode echocardiographic measurements for detection of left ventricular hypertrophy in necropsied subjects and in patients with systemic hypertension, mitral regurgitation and dilated cardiomyopathy. Am J Cardiol 1986,57:1388-1393.

19. Eichhorn P, Grimm J, Koch R, Hess O, Carroll J, Krayenbuehl HP. Left ventricular relaxation in patients with left ventricular hypertrophy secondary to aortic valve disease. Circulation 1982,65:1395-1404.

20. Murakami T, Hess OM, Gage JE, Grimm J, Krayenbuehl HP. Diastolic filling dynamics in patients with aortic stenosis. Circulation 1986:73:1162-1174. 21. Lorell BH, Grossman W. Cardiac hypertrophy: the consequences for diastole. JACC 1987,9:1189-1193.

22. Colan SD, Sanders SP, McPherson D, Borow KM. Left ventricular diastolic function in elite athletes with physiologic cardiac hypertrophy, $J A C C 1985 ; 6: 545$ 549.

23. Grossman W, McLaurin LP. Diastolic properties of the left ventricle. Ann Intern Med 1976;84:316-326.

24. Glantz SA, Parmley WW. Factors which affect the diastolic pressure-volume curve. Circ Res 1978:42:171-180.

25. Tamiya $K$, Sugawara $M$, Sakurai $Y$. Maximum lengthening velocity during isotonic relaxation at preload in canine papillary muscle. $A m J$ Physio 1979:237:H83-H89.

26. Gardin JM, Dabestani A, Rohan MK, Sklansky M, Garcia R, Knoll M, Henry WL. Nuninvasive studies of ventricular filling with Doppler echocardiography: effects of aging on early and late diastolic transmitral flow (abstr). $J A C C$ 1984:3:613.

27. Bryg RJ, Williams GA, Labovitz AJ. Effect of aging on left ventricular diastolic filling in normal subjects. Am J Cardiol 1987;59:971-974.

28. Choong CY, Herrmann HC, Weyman AE, Fifer MA. Preload dependence of Doppler-derived indexes of left ventricular diastolic function in humans $J A C C$ 1987;10:800-808 